\title{
Myocardial contrast echocardiography in the diagnosis of postoperative takotsubo myocardiopathy: case report and literature review
}

\author{
Jia-Hui Zeng ${ }^{\dagger}$, Wei Li ${ }^{\dagger}$, Feng-Juan Yao, Dong-Hong Liu, Cui-Ling Li, Yan-Qiu Liu, Rui Fan, Min Ye and Hong Lin* (1)
}

\begin{abstract}
Background: Takotsubo cardiomyopathy (TCM) is a brief ventricular dysfunction that usually occurs after emotional or physical stress. Here, we report a patient who underwent cardiac surgery and then developed TCM during the postoperative period.

Case presentation: A 51-year-old woman was admitted to our hospital complaining of chest tightness, palpitations and dyspnoea after activity. An echocardiogram performed by our hospital showed rheumatic heart disease (severe mitral stenosis and regurgitation) with normal cardiac function and wall motion. After mitral valve replacement, this patient developed heart failure with low blood pressure and tachycardia. Urgent bedside echocardiography demonstrated akinesis in the middle and apical segments of the left ventricle and a depressed ejection fraction (EF) of 36\%. Myocardial contrast echocardiography (MCE) showed similar enhancement intensity in the basal, middle and apical segments. Quantitative analysis showed approximately equivalent maximum intensity in these regions. The diagnosis was considered TCM instead of myocardial infarction. Then, an intra-aortic balloon pump was inserted to maintain effective circulation and reduce the postcardiac load. Given ventilation therapy, postoperative anticoagulation therapy and anti-infection treatment, the patient recovered quickly. In the follow-up examination, the patient remained asymptomatic and showed normalization of ventricular wall motion in the apical segment.
\end{abstract}

Conclusion: This report presents a case of TCM in which MCE was used to demonstrate intact microvascular perfusion despite apical akinesis. This report might support the use of MCE as a substitute for invasive coronary angiography.

Keywords: Takotsubo cardiomyopathy, Myocardial contrast echocardiography

\section{Background}

Takotsubo cardiomyopathy (TCM) is a brief ventricular dysfunction that occurs in the absence of obstructive coronary artery disease (CAD) [1]. TCM derives its name from the end-systolic shape of the left ventricle seen on left ventriculogram, which is similar to that of a Japanese octopus trap, and typically involves apical akinesis and compensatory basal hyperkinesis. Except for the typical form, a few cases of atypical (i.e. inverted) TCM have been described as well [2].

\footnotetext{
* Correspondence: hlin@163.com

†jia-Hui Zeng and Wei Li contributed equally to this work.

Department of Medical Ultrasonics, The First Affiliated Hospital of Sun

Yat-Sen University, No. 58, Zhongshan Road 2, Guangzhou 510080, People's Republic of China
}

(c) The Author(s). 2019 Open Access This article is distributed under the terms of the Creative Commons Attribution 4.0 International License (http//creativecommons.org/licenses/by/40/) which permits unrestricted use, distribution, and reproduction in any medium, provided you give appropriate credit to the original author(s) and the source, provide a link to the Creative Commons license, and indicate if changes were made. The Creative Commons Public Domain Dedication waiver (http://creativecommons.org/publicdomain/zero/1.0/) applies to the data made available in this article, unless otherwise stated. physical stress; a recent paper also suggested an association between TCM and depression/mood disorders [3]. However, TCM can also be related to the stress of surgery, in which case, it is called perioperative TCM (pTCM) [4]. TCM seems to mostly affect postmenopausal female due to influences of female hormones on sympathetic neuromodulation and endothelial function [5]. In general, TCM patients had a comparable long-term mortality risk with Acute Coronary Syndrome, but a recent paper suggests the prognosis varies with triggers [6].

In most cases, coronary angiography, computed tomography angiography, cardiac magnetic resonance and radionuclide scans are used to exclude coronary heart 


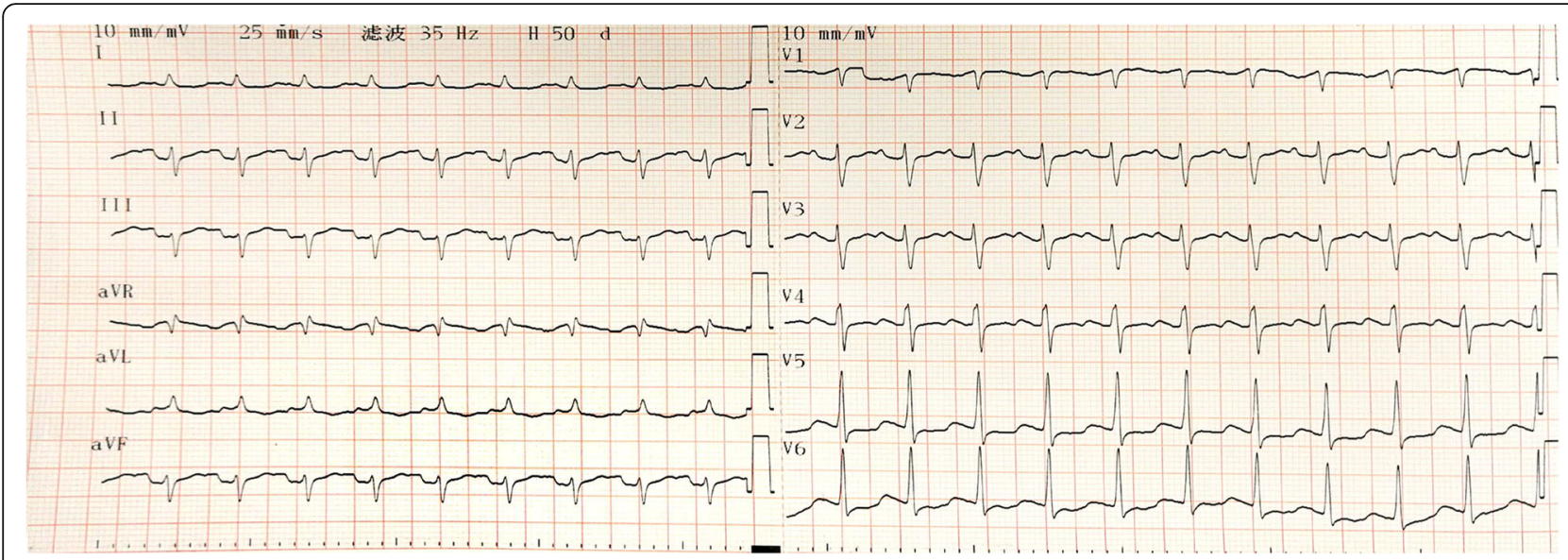

Fig. 1 Electrocardiogram at the time this patient had sudden heart failure. V5-6 ST-segment depression was $0.1 \mathrm{mV}$

disease. We present a case of postoperative TCM in a 51-year-old woman who underwent cardiac surgery. Intact microvascular myocardial perfusion was observed in myocardial contrast echocardiography (MCE) despite apical akinesis. This report supports the use of MCE as a substitute for invasive coronary angiography.

\section{Case presentation}

A 51-year-old woman was admitted to our hospital complaining of chest tightness, palpitations and dyspnoea after activity. On admission, physical examination revealed a normal state of consciousness, an average heart rate of 76 beats per minute (bpm), and a blood pressure of 111/70 $\mathrm{mmHg}$. Cardiac auscultation revealed variable first heart sound intensity and a diastolic murmur in the mitral stethoscope area. The other findings were unremarkable. The electrocardiogram showed atrial fibrillation. The echocardiogram performed by our hospital also showed rheumatic heart disease (severe mitral stenosis and regurgitation) with normal cardiac function and wall motion.

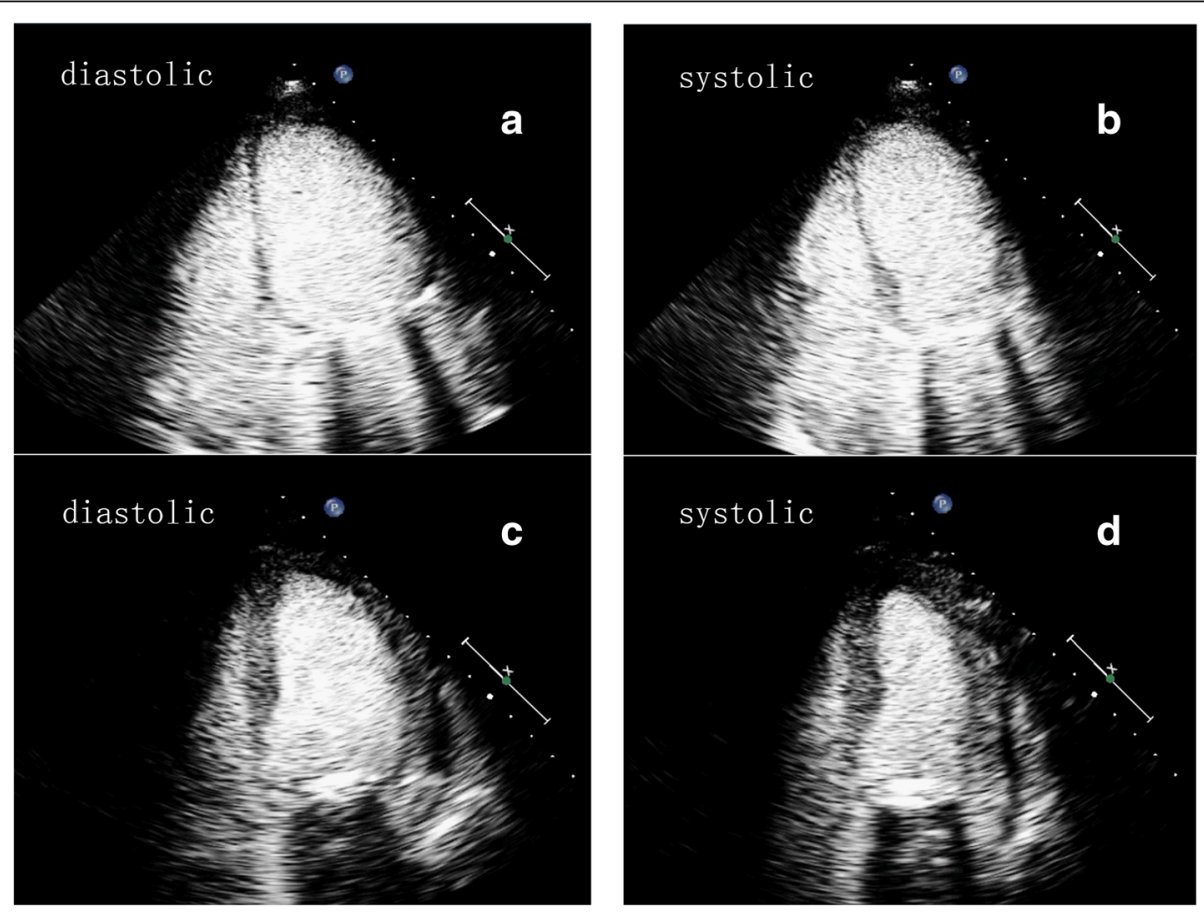

Fig. 2 Left ventricular opacification (LVO) performed on the second day after surgery ( $\mathbf{a}$ and $\mathbf{b}$ ) and two weeks later (c and $\mathbf{d}$ ). LVO performed on the second day after surgery ( $\mathbf{a}$ and $\mathbf{b}$ ) showed akinesis in the apical and middle segments of the left ventricle in the four-chamber view. LVO performed two weeks later (c and $\mathbf{d}$ ) showed that apical movement was significantly improved with a slight decrease in interventricular septal motion 


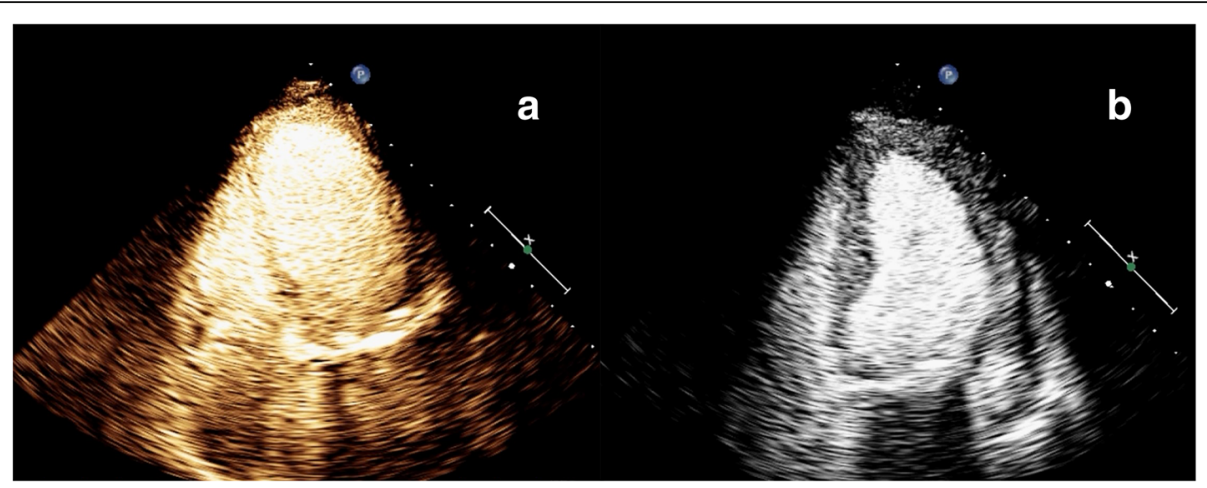

Fig. 3 Myocardial contrast echocardiography (MCE) performed on the second day after surgery (a) and two weeks later (b). Both myocardial contrast echocardiography (MCE) examinations showed homogeneous and equal enhancement intensity in the basal, middle and apical segments in the four-chamber view

After the completion of the preoperative examination, the patient was sent to the operating room for mitral valve replacement. The operation was successful. After the aorta was reopened, ventricular fibrillation occurred. Sinus rhythm was not restored until 5 rounds of electrical defibrillation had been performed. Not long after returning to the intensive care unit (ICU), this patient developed heart failure with low blood pressure (70 85/ $45 \sim 50 \mathrm{mmHg}$ ) and tachycardia (125-135 bpm). Blood gas analysis showed progressive lactic acidosis, and blood lactate increased from $2.4 \mathrm{mmol} / \mathrm{L}$ to $15.3 \mathrm{mmol} / \mathrm{L}$. Troponin $\mathrm{T}$ was slightly elevated compared to the preoperative level $(1.960 \mathrm{ng} / \mathrm{mL}$ vs $0.019 \mathrm{ng} / \mathrm{mL})$. N-terminal pro-brain natriuretic peptide levels increased markedly from $821.7 \mathrm{pg} / \mathrm{mL}$ to $21,025 \mathrm{pg} / \mathrm{mL}$. Electrocardiogram (ECG) (Fig. 1) showed that the V5-6 ST-segment depression was $0.1 \mathrm{mV}$. The bedside chest film showed a small amount of fluid in the left chest. Urgent bedside echocardiography demonstrated akinesis in the middle and apical segments of the left ventricle with depressed LV function (EF 36\%), while basal segments' movement were generally normal.

To determine the blood flow in the myocardium, myocardial contrast echocardiography (MCE) was performed immediately (Figs. 2a, b, and 3a). For the MCE examination, the ultrasound system was switched to the contrast mode, with a mechanical index of 0.1-0.5. MCE was performed using intravenous administration of 2.0 $\mathrm{mL}$ of SonoVue (Bracco, Milan, Italy). To achieve a balance among ultrasound intensity, penetration, and the duration of myocardial opacification, the contrast-specific imaging mode needed to be adjusted. Similar enhancement intensity was observed in the basal, middle and apical segments. Quantitative analysis also showed approximately equivalent maximum intensity values in these regions.

The diagnosis was considered TCM instead of myocardial infarction. The treatment mainly involved maintaining effective circulation and reducing the postcardiac load. After the administration of epinephrine and norepinephrine, the patient's blood pressure was still low. Considered the patient's condition as heart failure, an intra-aortic balloon pump was inserted. Although myocardial enzyme levels were elevated, the doctors did not perform treatment for coronary heart disease, considering the reason of tissue injury after heart surgery. The therapeutic regimen for this patient included ventilator-assisted ventilation, postoperative anticoagulation therapy, anti-infection treatment and other conservative treatments.

A week later, the patient underwent coronary angiography, and the results showed no significant narrowing of the coronary artery. This patient was extubated 13 days after surgery and was later weaned from epinephrine. Myocardial contrast echocardiography performed 2 weeks later (Figs. 2c, d, and 3b) showed that apical movement was significantly improved, with a slight decrease in interventricular septal motion. In addition, the perfusion of the myocardium was normal, with an EF (Simpson) of $52 \%$.

The clinical evolution was favourable, and the patient was discharged 3 weeks later. Before discharge, echocardiography showed that the artificial mitral valve function and the segmental wall movement were normal, with an $\mathrm{EF}$ of $72 \%$. One year later, the patient remained asymptomatic and showed normalization of ventricular wall motion in the apical segment.

\section{Discussion}

In this study, TCM was diagnosed in a middle-aged female patient who had slightly elevated myocardial enzyme levels, ECG abnormalities, normal epicardial coronary arteries, typical apical ballooning in echocardiography and normal myocardial perfusion in MCE according to the 2008 revised Mayo Clinic criteria [7]. The 
improvement of the left ventricular systolic dysfunction within 2 weeks was consistent with TCM.

We assessed the perfusion of the myocardium by using noninvasive $\mathrm{MCE}$, which indicated no microcirculatory dysfunction. In contrast to ST-segment elevation myocardial infarction, TCM is characterized by a greater elevation in brain natriuretic peptide and by less myonecrosis [8]. Moreover, the abnormal wall motion of the patient's left ventricle was not consistent with the blood flow distribution of an occluded epicardial coronary artery. The level of the biomarker troponin $\mathrm{T}$ was not proportional to the involved myocardial area [9]. In addition, MCE revealed no perfusion defects, which was consistent with the results of coronary angiography. Therefore, we believe that the integrity of the microvasculature can be revealed and coronary blood flow abnormalities can be excluded by performing MCE.

Some studies have used MCE to assess the perfusion of the myocardium in TCM patients. Studies have shown that compared with patients with acute myocardial infarction (AMI), patients with TCM have better preserved myocardial perfusion, as measured by MCE $[10,11]$. Additionally, in some rat model experiments, apical perfusion has not been found to be impaired in the early phase of TCM [12]. Our case also showed good perfusion in MCE despite the regional wall motion abnormalities in the acute phase of TCM, which confirmed that coronary microcirculation was normal. In Abe's study of 17 cases with TCM, a Doppler guidewire was used in 13 patients to assess coronary flow velocities [13]. In addition, MCE was used to assess the microcirculation of 1 patient. The examinations all showed normal coronary blood flow and were considered evidence of normal myocardial microcirculation in these patients. Hence, real-time MCE may be a useful and noninvasive diagnostic tool for differentiating TCM from AMI.

In most circumstances, emotional and physical stressors are thought to be the triggers for TCM. In recent years, perioperative factors have also attracted much attention as triggers of TCM [14-16]. In some cases, various perioperative factors, including intubation and extubation, radiofrequency ablation of atrial fibrillation in the region of the pulmonary veins, haemodynamic changes during the perioperative period, and excessive $\mathrm{CO}_{2}$ absorption, have been considered to contribute to the development of TCM by elevating catecholamine levels [1]. In this case, the patient had a history of atrial fibrillation. During the surgery, radiofrequency ablation was performed to disconnect the pulmonary vein. Blood gas analysis showed progressive lactic acidosis. All of these factors contributed to the occurrence of TCM in this patient.

\section{Conclusion}

TCM is a stress-induced transient ventricular dysfunction for which the prognosis is usually good, but there are still some patients with severe symptoms that can be life threatening. In surgical departments (not limited to cardiovascular surgery departments), when patients have symptoms similar to myocardial infarction along with arrhythmia or other risk factors, the possibility of TCM might be considered. It is vital that we identify this condition in patients at the time of onset and provide mechanical circulatory support devices. MCE is a powerful, safe and noninvasive method for early detection of abnormal ventricular wall movement and local microcirculation abnormalities and can be performed as an alternative to invasive coronary angiography. Based on the advantages mentioned above, MCE might also be used for regular TCM follow-up examinations.

\section{Abbreviations \\ AMl: Acute myocardial infarction; bpm: Beat per minute; CAD: Coronary artery disease; ECG: Electrocardiogram; EF: Ejection fraction; ICU: Intensive care unit; LV: Left ventricular; MCE: Myocardial contrast echocardiography; pTCM: Perioperative takotsubo cardiomyopathy; TCM: Takotsubo cardiomyopathy}

\section{Acknowledgments}

None.

\section{Funding}

This study was supported by National Natural Science Foundation of China (No: 81601500) and Natural Science Foundation of Guangdong Province (No: 2016A030310143)

Availability of data and materials

All available information is contained within the present manuscript.

Authors' contributions

$J H Z$ and $W L$ followed up the patient, performed the literature review, and drafted the manuscript. HL, DHLand FJY critically revised the manuscript and assisted in the literature review. CLL and RF collected the data and references. YQL and MY contributed to the analysis and interpretation of data. All authors have read and approved the final manuscript.

Ethics approval and consent to participate

Written informed consent was obtained from the patient. A copy of the written consent is available for review by the Editor of this journal.

Consent for publication

Written informed consent was obtained from the patient for publication of this case report and any accompanying images. A copy of the written consent is available for review by the Editor of this journal.

Competing interests

The authors declare that they have no competing interests.

\section{Publisher's Note}

Springer Nature remains neutral with regard to jurisdictional claims in published maps and institutional affiliations. 
Received: 18 June 2018 Accepted: 20 December 2018

Published online: 08 January 2019

\section{References}

1. Agarwal S, Bean MG, Hata JS, Castresana MR. Perioperative takotsubo cardiomyopathy: a systematic review of published cases. Semin Cardiothorac V. 2017;21(4):277-90.

2. Cadeddu C, Nocco S, Cadeddu F, Deidda M, Bassareo P, Serra A, Piga M, Mercuro G: Inverted takotsubo cardiomyopathy induced by dobutamine stress echocardiography with atypical presentation. Case Rep Cardiol 2011, 2011:413645.

3. F S, Carta MG, Montisci R, Preti A, Machado S, F M, Moro MMF, Meloni L. Takotsubo syndrome is associated with mood disorders and antidepressants use, not with anxiety and impairment of quality of life due to the psychiatric disorder. Clin Pract Epidemiol Ment Health. 2018;14:26-32.

4. Bybee KA, Kara T, Prasad A, Lerman A, Barsness GW, Wright RS, Rihal CS. Systematic review: transient left ventricular apical ballooning: a syndrome that mimics ST-segment elevation myocardial infarction. Ann Intern Med. 2004;141(11):858-65.

5. Gianni M, Dentali F, Grandi AM, Sumner G, Hiralal R, Lonn E. Apical ballooning syndrome or takotsubo cardiomyopathy: a systematic review. Eur Heart J. 2006;27(13):1523-9.

6. Ghadri JR, Kato K, Cammann VL, Gili S, Jurisic S, Di Vece D, Candreva A, Ding KJ, Micek J, Szawan KA, et al. Long-term prognosis of patients with Takotsubo syndrome. J Am Coll Cardiol. 2018;72(8):874-82.

7. Prasad A, Lerman A, Rihal CS. Apical ballooning syndrome (Tako-Tsubo or stress cardiomyopathy): a mimic of acute myocardial infarction. Am Heart J. 2008;155(3):408-17.

8. Madhavan M, Borlaug BA, Lerman A, Rihal CS, Prasad A. Stress hormone and circulating biomarker profile of apical ballooning syndrome (Takotsubo cardiomyopathy): insights into the clinical significance of B-type natriuretic peptide and troponin levels. Heart. 2009;95(17):1436-41.

9. Ramakrishna G, Ravi BS, Chandrasekaran K. Apical ballooning syndrome in a postoperative patient with normal microvascular perfusion by myocardial contrast echocardiography. Echocardiogr-J Card. 2005;22(7):606-10.

10. Choi JH, Nam JH, Son JW, Lee SH, Kim U, Park JS, Shin DG, Kim YJ, Hong GR. Clinical usefulness of myocardial contrast echocardiography to detect stress-induced cardiomyopathy in the emergency department. Circ J. 2012; 76(6):1393-8.

11. Min SY, Song JM, Shin Y, Sin MJ, Kim DH, Kang DH, Song JK. Quantitative segmental analysis of myocardial perfusion to differentiate stress cardiomyopathy from acute myocardial infarction: a myocardial contrast echocardiography study. Clin Cardiol. 2017;40(9):679-85.

12. Redfors B, Shao YZ, Wikstrom J, Lyon AR, Oldfors A, Gan LM, Omerovic E. Contrast echocardiography reveals apparently normal coronary perfusion in a rat model of stress-induced (Takotsubo) cardiomyopathy. Eur Heart J-Card Img. 2014;15(2):152-7.

13. Abe $\mathrm{Y}$, Kondo M, Matsuoka R, Araki M, Dohyama K, Tanio H. Assessment of clinical features in transient left ventricular apical ballooning. J Am Coll Cardiol. 2003:41(5):737-42.

14. Bruckman KC, Taub DI, McNulty SE. Takotsubo cardiomyopathy precipitated by maxillofacial surgery and general anesthesia: a case report and review of literature. J Oral Maxil Surg. 2013;71(12).

15. O'Reardon JP, Lott JP, Akhtar UW, Cristancho P, Weiss D, Jones N. Acute coronary syndrome (Takotsubo cardiomyopathy) following electroconvulsive therapy in the absence of significant coronary artery disease: case report and review of the literature. J Ect. 2008;24(4):277-80

16. Minatoguchi M, Itakura A, Takagi E, Nishibayashi M, Kikuchi M, Ishihara O. Takotsubo cardiomyopathy after cesarean: a case report and published work review of pregnancy-related cases. J Obstet Gynaecol Re. 2014;40(6): $1534-9$

Ready to submit your research? Choose BMC and benefit from:

- fast, convenient online submission

- thorough peer review by experienced researchers in your field

- rapid publication on acceptance

- support for research data, including large and complex data types

- gold Open Access which fosters wider collaboration and increased citations

- maximum visibility for your research: over $100 \mathrm{M}$ website views per year

At $\mathrm{BMC}$, research is always in progress.

Learn more biomedcentral.com/submissions 